\title{
Fonoaudiologia nas práticas educacionais de formação de jornalistas - estudo de revisão
}

\author{
Speech, language pathology and audiology \\ in educational practices with training \\ journalists - a review study
}

\section{Fonoaudiología en las prácticas educativas de formación de periodistas - estudio de revisión}

\author{
Regina Zanella Penteado* \\ Ana Carolina de Assis Moura Ghirardi**
}

\section{Resumo}

$\mathrm{O}$ artigo tem por objetivo dar destaque à produção bibliográfica de experiências fonoaudiológicas em processos de formação de jornalistas, e capturar o enfoque educacional nessa produção. Para tanto, apresenta uma revisão da literatura referente às experiências de atuação fonoaudiológica em práticas educacionais e processos de formação de jornalistas. A revisão se deu mediante buscas on-line (SciELO $e$ Google Acadêmico) e processo de seleção com aplicação de critérios de relevância, resultando em sete publicações. As experiências são ambientadas em Universidades e desenvolvidas em contextos formais e não-formais de formação do jornalista; geralmente por meio de ações processuais, caracterizadas como cursos, oficinas e vivências atreladas a projetos de pesquisa e extensão. Predominam os temas e conteúdos: Expressividade e Saúde Vocal (100\%); Anátomo/fisiologia da Fonação ou Produção da Voz, Aquecimento/Desaquecimento Vocal, Exercícios Vocais e Psicodinâmica Vocal (57\% cada um deles). As ações apresentam caráter tecnicista/instrumental sob enfoques organicistas/fisiológicos vinculados à vertente da saúde. O caráter educativo/educacional das ações, quando existente, se encontra restrito aos fins de promoção do cuidado e da saúde. A expressividade pode ser uma chave para o estreitamento

\footnotetext{
* Universidade Estadual Paulista Júlio de Mesquita Filho (UNESP) Rio Claro, SP, Brasil e Universidade Metodista de Piracicaba (UNIMEP), Piracicaba, SP, Brasil.

** Universidade Federal de Santa Catarina (UFSC), Florianópolis, SC, Brasil.

Contribuições das autoras:

RZP: responsável pela concepção, delineamento, desenvolvimento do estudo; coleta, interpretação e análise de dados; elaboração, revisão e aprovação da versão final do artigo a ser publicada;

ACAMG: responsável pela análise de dados e elaboração, revisão, aprovação e tradução da versão final do artigo a ser publicada..
}

E-mail para correspondência: Regina Zanella Penteado - rzpenteado@unimep.br

Recebido: 21/02/2017

Aprovado: 02/08/2017 
do diálogo entre Comunicação, Fonoaudiologia e Educação; especialmente para a potencialização de um enfoque educacional nas práticas fonoaudiológicas em formação de profissionais de Comunicação e de Educação.

Palavras-chave: Fonoaudiologia; Jornalismo; Linguagem; Educação; Comunicação; Voz.

\section{Abstract}

The purpose of this paper is to highlight the literature and experiences in Speech-Language Pathology and Audiology in the educational processes of journalists, while capturing the educational emphasis of these references. Therefore, this study presents a literature review regarding Speech-Language Pathology and Audiology experiences in educational practices during the training processes of journalists. The review was conducted through online searches (SciELO and Google Scholar) followed by a selection process through relevance criteria, resulting in seven references. The experiences are set in formal and nonformal educational contexts for journalists, usually happening through procedural actions characterized as courses, workshops and experiences linked to research and university extension projects. The main themes and contents are: Expressivity and Vocal Health (100\%); Phonation Anatomy/Physiology or Voice Production, Vocal warm-up/cool down; Vocal Exercises and Vocal Psychodynamics (57\% each). The actions have a technical/instrumental character with organic/physiological approaches linked to the field of health. The formative/educational character of these actions, when present, is restrained to the promotion of health and care. Expressivity may be a key towards better dialogue between Communication, Speech-Language Pathology and Audiology and the field of Education, especially when enhancing the educational approach in Speech-Language Pathology and Audiology practices in the education of Communication and Education professionals.

Keywords: Speech, Language and Hearing Sciences; Journalism; Language; Education; Communication; Voice.

\section{Resumen}

El artículo tiene por objetivo destacar la producción bibliográfica de experiencias fonoaudiológicas en procesos de formación de periodistas, y capturar el enfoque educativo en dicha producción. Para ello, presenta una revisión de la literatura sobre las experiencias de actuación fonoaudiológica en prácticas educativas y procesos de formación de periodistas. La revisión se llevó a cabo mediante la búsqueda on-line (SciELO y Google Académico), y proceso de selección con aplicación de criterios de relevancia, resultando en siete publicaciones. Las experiencias se ambientan en Universidades y se desarrollan en contextos formales y no formales de la formación del periodista; generalmente a través de acciones procesales, caracterizadas como cursos, talleres e vivencias vinculadas a proyectos de investigación y extensión. Predominan los temas y contenidos: Expresividad y Salud Vocal (100\%); Anatomía/fisiología de la Fonación o Producción de la Voz, Calentamiento/Enfriamiento Vocal, Ejercicios Vocales y Sicodinámica Vocal ( $57 \%$ cada uno de ellos). Las acciones presentan carácter tecnicista/instrumental bajo enfoques organicistas/fisiológicos relacionados a la vertiente de la salud. El carácter educativo/educacional de las acciones, si existe, se limita a propósitos de promoción y cuidado de la salud. La expresividad puede ser una clave para el estrechamiento del diálogo entre Comunicación, Fonoaudiología y Educación; especialmente para la potenciación de un enfoque educacional en las prácticas de fonoaudiología, en la formación de los profesionales de la Comunicación y de la Educación.

Palabras clave: Fonoaudiología; Periodismo; Lenguaje; Educación; Comunicación; Voz. 


\section{Introdução}

As mudanças nas condições e organização do processo de trabalho em comunicação e do mundo do trabalho jornalístico, ocorridas nos últimos anos, geram demandas relacionadas à ampliação e à diversificação das habilidades comunicacionais e expressivas desses profissionais ${ }^{1-3}$.

No jornalismo de televisão, as mudanças de linguagem, cenário, apresentação e a inserção de novas tecnologias atualizam a necessidade da formação do jornalista em relação à expressividade ${ }^{1,2}$.

Entendemos ser oportuno esclarecer que a expressividade é compreendida, neste estudo, na perspectiva da Fonoaudiologia, levando em conta que ela engloba aspectos e recursos verbais, vocais, não verbais e pausas ${ }^{1}$. Os recursos verbais são as palavras, a seleção dos vocábulos, a construção frasal, o texto. Os recursos vocais são qualidade vocal, tipos de voz e os parâmetros e recursos vocais tais como pitch: agudo, médio, grave; loudness: fraca, média, forte; velocidade: lenta, média, rápida; articulação: imprecisa, sub-articulada, precisa, sobrearticulada, exagerada; ressonância: difusa/ equilibrada, ou com foco predominante: nasal, oral, laringo-faríngeo; modulação: monótona, repetitiva, rica, exagerada; coordenação pneumofonoarticulatória: coordenada ou incoordenada. Os recursos não verbais dizem respeito ao corpo em suas posturas, posições, movimentos, deslocamentos, danças, gestos, olhares, expressões faciais e articulatórias; meneios de cabeça, aparência física e indumentária. Complementarmente, as pausas silenciosas contribuem para a delimitação de turnos de fala e produção de sentidos.

No entanto, a linguagem e a expressividade ainda não recebem a devida atenção nos processos educacionais de jornalistas: são escassas as obras que abordam estes aspectos e poucos os cursos de graduação em Jornalismo que têm disciplinas cujo foco central seja a comunicação profissional ${ }^{3-5}$.

Há várias publicações fonoaudiológicas que tratam de pesquisas e práticas junto a jornalistas, mas poucas com impacto e importância em referenciar e orientar a formação do fonoaudiólogo dirigida a comunicadores, como as obras que compõem a série "Fonoaudiologia e Telejornalismo" 6-8 e uma obra que sintetiza os principais tópicos de expressividade tratados em linguagem simples e direcionada ao público que depende da comunicação em seu trabalho ${ }^{9}$ Contudo, cabe ressaltar que estas principais referências da Fonoaudiologia referentes à atuação junto ao Jornalismo são oriundas de experiências que comportam o enfoque da assessoria - envolvendo profissionais, contextos, realidades e demandas do trabalho jornalístico que guardam as especificidades e as peculiaridades da lógica de uma determinada empresa de comunicação.

O presente artigo busca ampliar a compreensão da interlocução da Fonoaudiologia com o Jornalismo a partir de um enfoque que não seja restrito ao da assessoria.

O objetivo deste estudo é dar destaque à produção bibliográfica que apresenta as experiências fonoaudiológicas desenvolvidas nos processos de formação de jornalistas e analisar o caráter das ações realizadas e destacar o enfoque educacional nessa produção.

Este artigo apresenta uma revisão da literatura das experiências da Fonoaudiologia em práticas educacionais e processos de formação de jornalistas.

\section{Métodos}

\section{Estudo de Revisão}

Algumas perguntas orientam a revisão: como se apresenta a produção bibliográfica referente às experiências da Fonoaudiologia em processos educacionais e de formação de jornalistas? Quais são os contextos e os temas/conteúdos nelas abordados e as relações com o trabalho jornalístico? Qual o caráter das ações realizadas? A produção apresenta enfoque educacional?

\section{Processo de busca}

As fontes de dados para as buscas foram constituídas pelas bases $S c i E L O$ e Google Acadêmico. As buscas foram, portanto, realizadas de modo on-line, e no mês de maio de 2016.

Uma vez acessadas as bases $S c i E L O$ e Google Acadêmico, as buscas foram feitas a partir do emprego dos descritores Fonoaudiologia (+) Jornalismo (+) Expressividade. Não houve delimitação de período de tempo das publicações no momento das buscas.

Esta busca inicial resultou em um levantamento de 1032 publicações (Google Acadêmico=1031 e SciELO=1).

A seguir, os resultados deste levantamento inicial foram submetidos a um processo de seleção que envolveu inclusões e exclusões. 
As etapas e os critérios implicados nesse processo de seleção são descritos e apresentados a seguir:

\section{Etapas de seleção}

Sobre os resultados iniciais recaiu um processo de seleção que envolveu leitura de títulos e resumos e, quando necessário, do texto na íntegra, o qual implicava em aplicação de critérios de seleção e de relevância com aceitação/inclusão e rejeição/ exclusão.

Foram aceitas/incluídas as publicações que respondiam às seguintes condições em relação às ações realizadas e experiências relatadas:

a) A população, ou os sujeitos envolvidos, deveria ser composta por estudantes de jornalismo (ainda que se saiba que muitos deles já atuam no mercado - uma vez que o diploma, apesar de relevante, há alguns anos deixou de ser exigência para o trabalho em jornalismo);

b) O trabalho com a expressividade dos sujeitos deveria integrar as ações;

c) A experiência relatada deveria se referir a uma ação no campo educacional/formativo de jornalistas (podendo ser "cursos", "oficinas", "vivências", "treinamentos" oferecidos sob a chancela de instituições educacionais, cursos, faculdades, Universidades ou de forma autônoma, sediados e/ou promovidos em clínicas, consultórios, sindicatos, empresas, etc);

d) A publicação deveria configurar artigo de periódico, anais de congresso, monografia, dissertação ou tese;

e) A publicação deveria ser feita nos últimos 15 anos (2000 a 2016);

f) A publicação deveria ser feira nas línguas portuguesa, inglesa ou espanhola;

g) O texto da publicação deveria estar disponível para acesso on-line

Foram rejeitadas/excluídas as publicações:

a) Que não se adequavam aos critérios de aceitação/inclusão anteriormente descritos;

b) Que se apresentavam duplicadas;

c) Que se referiam a traduções/versões de um mesmo texto (por exemplo: o mesmo artigo publicado duas vezes no mesmo periódico: uma versão em língua inglesa e outra em língua portuguesa - uma das versões seria excluída do estudo); d) Que eram referentes a relatos de experiências de processos de consultoria e/ou assessoria fonoaudiológica a jornalistas em resposta a demandas e problemas como alterações de fala, voz, linguagem, motricidade orofacial ou distúrbios da comunicação;

e) Que configuravam estudos teórico-conceituais e relatos de processos clínico-terapêuticos;

f) Que configuravam relatos de processos avaliativos, diagnósticos ou triagens;

g) Que configuravam levantamentos e caracterizações de perfis, comportamentos e conhecimentos relacionados aos usos da voz e às queixas $\mathrm{e}$ problemas de saúde relacionados à voz.

Cabe, aqui, o esclarecimento de que a opção pelo critério de exclusão dos estudos de caráter clínico-terapêutico, avaliativo e epidemiológico não se dá por desmerecer, em hipótese alguma, a importância e a relevância de tais estudos; ou por desconsiderar que toda ação possa ter um efeito educativo ou terapêutico; e, muito menos, por negar que as demandas, os problemas, as dificuldades e as necessidades dos sujeitos são mobilizadoras para a busca da ação transformadora. Ocorre que a inclusão de tais ações no processo de seleção acabaria por desconfigurar a natureza do estudo de revisão, tendo em vista os seus objetivos e enfoques claramente voltados para as experiências da Fonoaudiologia em práticas educacionais e processos de formação de jornalistas - ou seja: entendemos, aqui, que a formação do jornalista poderia contemplar a atuação da fono a despeito da existência de problemas, alterações e distúrbios, que a Fonoaudiolgia poderia ter uma inserção educacional no processo de formação de jornalistas que dispense a justificativa pela patologia e passe a constituir outros sentidos, no campo educacional.

Finalizado o processo de seleção, a resultante foi composta por sete publicações, as quais passaram a integrar a presente revisão.

As publicações selecionadas para a revisão foram lidas integralmente e os seus dados sintetizados, organizados e categorizados a partir dos seguintes itens:

- Identificação: autor, ano e tipo de publicação.

- Caracterização (tipo de ação).

- Coordenação (áreas envolvidas).

- Ambientação (local de desenvolvimento).

- Contexto de Educação Formal ou Não-Formal em relação à grade curricular e/ou atividades 
acadêmicas em Curso de Jornalismo (Formal: oferecida como disciplina integrante da grade curricular ou como projetos de pesquisa e extensão; Não-Formal: oferecida de forma autônoma ou com apoio institucional de cursos, faculdades, universidades, empresas, órgãos, outras entidades).

- Temas e/ou conteúdos abordados, objetivos e enfoques - recorte da ação fonoaudiológica, com especial atenção para a expressividade. Cabe observar que, sempre que a experiência relatada na publicação envolvia atuação de outras áreas, o recorte apresentado no quadro diz respeito especialmente àqueles temas e/ou conteúdos referentes à prática fonoaudiológica.

- Estratégia de desenvolvimento: pontual (ação constituída por um evento único ou até dois encontros) ou processual (constituído por três ou mais encontros).

\section{Resultados}

O quadro 1 apresenta os resultados das publicações que integram o estudo de revisão, com destaque aos aspectos identificados a partir do item anteriormente referido, de tratamento dos dados:

Quadro 1. Apresentação dos dados das publicações que integram a revisão.

\begin{tabular}{|c|c|c|c|c|c|}
\hline $\begin{array}{l}\text { AUTOR } \\
\text { ANO } \\
\text { TIPO }\end{array}$ & $\begin{array}{l}\text { CARACTERIZAÇÃO, } \\
\text { COORDENAÇÃO, } \\
\text { AMBIENTAÇÃO, } \\
\text { CONTEXTO DE } \\
\text { EDUCAÇÃO }\end{array}$ & SUJEITOS & $\begin{array}{l}\text { TEMAS E/OU } \\
\text { CONTEÚDOS }\end{array}$ & $\begin{array}{c}\text { OBJETIVOS E } \\
\text { ENFOQUES } \\
\text { EM TRABALHAR A } \\
\text { EXPRESSIVIDADE }\end{array}$ & $\begin{array}{c}\text { ESTRATÉGIAS DE } \\
\text { DESENVOLVIMENTO }\end{array}$ \\
\hline $\begin{array}{l}\text { TRINDADE } \\
\begin{array}{c}(2008)^{10} \\
*\end{array} \\
\text { Dissertação }\end{array}$ & $\begin{array}{c}\text { Vivência Grupal } \\
* \\
\text { Coordenação: } \\
\text { fonoaudióloga } \\
* \\
\text { Ambiente Universitário - } \\
\text { TV universitária. } \\
* \\
\text { projeto de pesquisa } \\
* \\
\text { Não-Formal } \\
* \\
\text { Formação Inicial }\end{array}$ & $\begin{array}{l}\text { Repórteres } \\
\text { (estudantes/ } \\
\text { estagiários) } \\
\text { de um núcleo } \\
\text { de produção } \\
\text { televisiva e } \\
\text { videográfica da } \\
\text { Universidade }\end{array}$ & $\begin{array}{c}\text { Interação entre } \\
\text { recursos verbais, } \\
\text { vocais e não- } \\
\text { verbais da } \\
\text { expressividade; } \\
* \\
\text { Credibilidade } \\
\text { e clareza na } \\
\text { transmissão da } \\
\text { notícia } \\
* \\
\text { Avaliação } \\
\text { fonoaudiológica e } \\
\text { de telespectadores } \\
* \\
\text { Saúde Vocal }\end{array}$ & $\begin{array}{c}\text { Percepção, } \\
\text { sensibilização, } \\
\text { conscientização e } \\
\text { treinamento quanto } \\
\text { aos parâmetros } \\
\text { vocais para } \\
\text { aprimoramento } \\
\text { dos recursos } \\
\text { expressivos e } \\
\text { das habilidades } \\
\text { comunicativas }\end{array}$ & $\begin{array}{c}\text { Processual: seis semanas, } \\
\text { encontros de } 90 \text { minutos. } \\
* \\
\text { Questionários } \\
* \\
\text { Folhetos de Saúde Vocal } \\
* \\
\text { Avaliação fonoaudiológica pré } \\
\text { e pós } \\
* \\
\text { Alongamentos e exercícios } \\
\text { vocais, respiratórios e } \\
\text { articulatórios, trava-línguas, } \\
\text { sequências articulatórias, } \\
\text { frases, rimas, poemas } \\
* \\
\text { Figuras, vídeos, multimídia } \\
* \\
\text { Simulações de fala e } \\
\text { de reportagens com } \\
\text { videogravações. }\end{array}$ \\
\hline $\begin{array}{c}\text { AZEVEDO, } \\
\text { FERREIRA, } \\
\text { KYRILLOS } \\
\left(\begin{array}{c}2009)^{11} \\
*\end{array}\right. \\
\text { Artigo em } \\
\text { Periódico }\end{array}$ & $\begin{array}{c}\text { Ação Grupal } \\
* \\
\text { Coordenação: } \\
\text { fonoaudióloga } \\
* \\
\text { Ambiente Universitário - } \\
\text { TV Universitária } \\
* \\
\text { projeto de pesquisa } \\
* \\
\text { Não-Formal } \\
* \\
\text { Formação Inicial e } \\
\text { Continuada / Em serviço }\end{array}$ & $\begin{array}{c}\text { Repórteres e } \\
\text { apresentadores } \\
\text { de uma } \\
\text { televisão } \\
\text { universitária } \\
\text { (dois } \\
\text { estudantes de } \\
\text { Jornalismo; } \\
\text { dois } \\
\text { profissionais } \\
\text { jornalistas } \\
\text { e dois de } \\
\text { Comunicação- } \\
\text { Multimeios). }\end{array}$ & $\begin{array}{c}\text { Produção da voz } \\
* \\
\text { Anatomofisiologia } \\
\text { do aparelho } \\
\text { fonador } \\
* \\
\text { Saúde Vocal } \\
* \\
\text { Aquecimento Vocal } \\
* \\
\text { Psicodinâmica } \\
\text { Vocal } \\
* \\
\text { Recursos vocais, } \\
\text { não-verbais, } \\
\text { pausas e ênfases } \\
* \\
\text { Técnicas para uso } \\
\text { vocal profissional }\end{array}$ & $\begin{array}{l}\text { Abordar, treinar } \\
\text { e conscientizar } \\
\text { os telejornalistas } \\
\text { sobre o uso dos } \\
\text { recursos vocais } \\
\text { (ênfase, curva } \\
\text { melódica, } \\
\text { articulação, } \\
\text { velocidade e } \\
\text { pausas e os } \\
\text { recursos não- } \\
\text { verbais (postura } \\
\text { corporal, expressão } \\
\text { facial, meneios de } \\
\text { cabeça e gestos) }\end{array}$ & $\begin{array}{c}\text { Processual: ao longo de } \\
\text { quatro semanas, encontros } \\
\text { semanais de duas horas. } \\
* \\
\text { Dinâmicas e estratégias que } \\
\text { favorecem percepção de si e } \\
\text { dos outros e conhecimento de } \\
\text { fatores favoráveis/prejudiciais } \\
\text { à voz. } \\
* \\
\text { Exercícios, sequências } \\
\text { articulatórias, trava-línguas } \\
\text { e técnicas vocais } \\
* \\
\text { Explanações, leituras, } \\
\text { interpretação de textos, } \\
\text { simulações de entrevista e } \\
\text { reportagem; gravações para } \\
\text { análise da psicodinâmica e } \\
\text { recursos vocais, não-verbais } \\
\text { e ênfases. } \\
* \\
\text { Questionários } \\
* \\
\text { Avaliação pré e pós. }\end{array}$ \\
\hline
\end{tabular}




\begin{tabular}{|c|c|c|c|c|c|}
\hline $\begin{array}{l}\text { AUTOR } \\
\text { ANO } \\
\text { TIPO }\end{array}$ & $\begin{array}{l}\text { CARACTERIZAÇÃO, } \\
\text { COORDENAÇÃOO, } \\
\text { AMBIENTAÇÃO, } \\
\text { CONTEXTO DE } \\
\text { EDUCAÇÃO }\end{array}$ & SUJEITOS & $\begin{array}{l}\text { TEMAS E/OU } \\
\text { CONTEÚDOS }\end{array}$ & $\begin{array}{c}\text { OBJETIVOS E } \\
\text { ENFOQUES } \\
\text { EM TRABALHAR A } \\
\text { EXPRESSIVIDADE }\end{array}$ & $\begin{array}{c}\text { ESTRATÉGIAS DE } \\
\text { DESENVOLVIMENTO }\end{array}$ \\
\hline $\begin{array}{c}\text { PENTEADO } \\
\text { TREVISAN } \\
\text { GONÇALVES } \\
(2010)^{12} \\
* \\
\text { Anais } \\
\text { Congresso }\end{array}$ & $\begin{array}{c}\text { Trabalho Grupal em } \\
\text { contexto de disciplina } \\
\text { curricular } \\
* \\
\text { Coordenação: docente } \\
\text { fonoaudióloga } \\
* \\
\text { Ambiente: Universitário - } \\
\text { disciplina de um Curso de } \\
\text { Graduação em Jornalismo } \\
* \\
\text { Formal } \\
\text { (disciplina) } \\
* \\
\text { Formação Inicial }\end{array}$ & $\begin{array}{l}\text { Estudantes de } \\
\text { Jornalismo }\end{array}$ & $\begin{array}{c}\text { Valoração, usos } \\
\text { e cuidados com a } \\
\text { voz profissional, } \\
\text { saúde geral e } \\
\text { qualidade de vida. } \\
* \\
\text { Condiç̃es e } \\
\text { organização do } \\
\text { trabalho em } \\
\text { Jornalismo }\end{array}$ & $\begin{array}{c}\text { Uso profissional } \\
\text { da voz e } \\
\text { expressividade } \\
\text { (recursos vocais } \\
\text { e não-verbais) } \\
\text { na relação com a } \\
\text { saúde, o trabalho e } \\
\text { a qualidade de vida }\end{array}$ & $\begin{array}{l}\text { Processual: contexto de } \\
\text { disciplina semestral } \\
\quad * \\
\text { Experiência de visitas a } \\
\text { empresas de comunicação; } \\
\text { entrevistas com jornalistas; } \\
\text { observação de situações de } \\
\text { trabalho, desenvolvimento de } \\
\text { trabalho teórico-prático sobre } \\
\text { relações entre expressividade, } \\
\text { saúde, trabalho e qualidade } \\
\text { de vida do jornalista. }\end{array}$ \\
\hline $\begin{array}{c}\text { CAJAZEIRA } \\
(2013)^{13} \\
* \\
\text { Artigo em } \\
\text { Periódico }\end{array}$ & $\begin{array}{c}\text { Projeto de extensão: } \\
\text { "Locução e técnica vocal } \\
\text { para comunicadores" } \\
* \\
\text { Coordenação: } \\
\text { professor da disciplina } \\
\text { de Telejornalismo, } \\
\text { com participação } \\
\text { multidisciplinar e } \\
\text { colaboração de bolsista, } \\
\text { técnicos e profissionais } \\
\text { das áreas de Comunicação } \\
\text { Social, Medicina, Teatro e } \\
\text { Fonoaudiologia. } \\
* \\
\text { Ambiente: Universitário } \\
\text { - projeto de extensão / } \\
\text { Curso de Jornalismo } \\
* \\
\text { Formal } \\
\text { (projeto extensão) } \\
* \\
\text { Formação Inicial }\end{array}$ & $\begin{array}{l}\text { Estudantes de } \\
\text { Jornalismo }\end{array}$ & 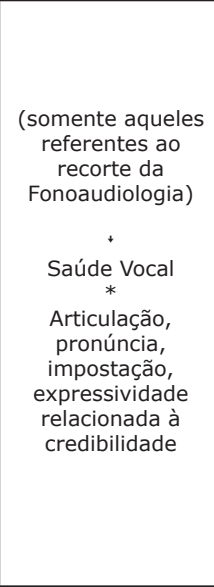 & $\begin{array}{c}\text { FONO: } \\
\text { Expressividade } \\
\text { relacionada com a } \\
\text { credibilidade } \\
\text { PROGRAMA } \\
\text { EXTENSÃO: } \\
\text { Promover ações } \\
\text { educativas } \\
\text { integradas, } \\
\text { voltadas às } \\
\text { necessidades } \\
\text { básicas de } \\
\text { informação, } \\
\text { educação e } \\
\text { saúde vocal dos } \\
\text { comunicadores. }\end{array}$ & $\begin{array}{c}\text { FONO: } \\
\text { Pontual: ação fonoaudiológica: } \\
\text { uma videoconferência (90 } \\
\text { minutos). } \\
* \\
\text { exercícios vocais (dicção); } \\
\text { cuidados com a voz. }\end{array}$ \\
\hline $\begin{array}{l}\text { PERREGIL } \\
\text { SILVA } \\
(2013)^{14} \\
* \\
\text { Anais } \\
\text { Congresso }\end{array}$ & $\begin{array}{c}\text { Oficinas Fonoaudiológicas } \\
* \\
\text { Coordenação: Docente da } \\
\text { área de Comunicação e } \\
\text { fonoaudióloga } \\
* \\
\text { Ambiente: Universitário } \\
\text { - projeto de extensão } \\
\text { do Dep. de Comunicação } \\
\text { envolvendo uma webradio } \\
\text { universitária } \\
* \\
\text { Formal } \\
\text { (projeto extensão) } \\
* \\
\text { Formação Inicial }\end{array}$ & $\begin{array}{l}\text { Locutores e } \\
\text { estudantes } \\
\text { de Jornalismo } \\
\text { integrantes } \\
\text { do Núcleo } \\
\text { de Locução } \\
\text { Radiofônica da } \\
\text { webradio }\end{array}$ & $\begin{array}{c}\text { Respiração, } \\
\text { articulação e } \\
\text { entonação/ } \\
\text { modulação. } \\
* \\
\text { Aquecimento vocal } \\
* \\
\text { Fisiologia da } \\
\text { Fonação } \\
* \\
\text { Psicodinâmica } \\
\text { Vocal } \\
* \\
\text { Saúde Vocal } \\
* \\
\text { Avaliações }\end{array}$ & $\begin{array}{c}\text { FONO: } \\
\text { Dar ferramentas } \\
\text { básicas } \\
\text { para que os } \\
\text { participantes } \\
\text { possam aprender a } \\
\text { usar a voz } \\
\text { NÚCLEO DE } \\
\text { LOCUÇÃO: } \\
\text { Busca de locução } \\
\text { mais natural } \\
\text { combinando } \\
\text { preferências } \\
\text { e estilos dos } \\
\text { locutores à editoria }\end{array}$ & $\begin{array}{c}\text { FONO: } \\
\text { Processual - um ano. } \\
\text { Explanações, exercícios } \\
\text { vocais, trava-línguas; } \\
\text { Falar com ampla abertura de } \\
\text { boca; alternância de vogais } \\
\text { a/i/u; mobilidade de língua. } \\
* * \\
\text { Avaliação semanal da locução } \\
\text { veiculada }\end{array}$ \\
\hline
\end{tabular}




\begin{tabular}{|c|c|c|c|c|c|}
\hline $\begin{array}{c}\text { AUTOR } \\
\text { ANO } \\
\text { TIPO }\end{array}$ & $\begin{array}{l}\text { CARACTERIZAÇÃO, } \\
\text { COORDENAÇÃO, } \\
\text { AMBIENTAÇÃO, } \\
\text { CONTEXTO DE } \\
\text { EDUCAÇÃO }\end{array}$ & SUJEITOS & $\begin{array}{l}\text { TEMAS E/OU } \\
\text { CONTEÚDOS }\end{array}$ & $\begin{array}{c}\text { OBJETIVOS E } \\
\text { ENFOQUES } \\
\text { EM TRABALHAR A } \\
\text { EXPRESSIVIDADE }\end{array}$ & $\begin{array}{c}\text { ESTRATÉGIAS DE } \\
\text { DESENVOLVIMENTO }\end{array}$ \\
\hline $\begin{array}{l}\text { PENTEADO } \\
\text { SANTOS } \\
(2015)^{15} \\
* \\
\text { Artigo em } \\
\text { Periódico }\end{array}$ & $\begin{array}{c}\text { Vivência Grupal } \\
* \\
\text { Coordenação: docente } \\
\text { e discentes envolvidos } \\
\text { com um estágio } \\
\text { em Fonoaudiologia } \\
\text { Comunitária } \\
* \\
\text { Ambiente Universitário } \\
\text { - Grupo por adesão } \\
\text { espontânea } \\
* \\
\text { Não-Formal } \\
* \\
\text { Formação Inicial e } \\
\text { Continuada - Em Serviço }\end{array}$ & $\begin{array}{l}\text { Pessoas que } \\
\text { fazem (ou } \\
\text { não) uso } \\
\text { profissional da } \\
\text { voz falada e/ } \\
\text { ou cantada. } \\
\text { (inclui } \\
\text { estudantes e } \\
\text { profissionais } \\
\text { de } \\
\text { Jornalismo). }\end{array}$ & $\begin{array}{c}\text { Abordagem social } \\
\text { da voz } \\
* \\
\text { Avaliação vocal } \\
* \\
\text { Tipos de voz } \\
* \\
\text { Produção vocal } \\
* \\
\text { Psicodinâmica } \\
\text { Vocal } \\
* \\
\text { Expressividade } \\
\text { vocal e não-verbal } \\
* \\
\text { Resistência vocal } \\
* \\
\text { Saúde Vocal } \\
* \\
\text { Aquecimento e } \\
\text { desaquecimento } \\
\text { vocal } \\
* \\
\text { Condições de } \\
\text { trabalho }\end{array}$ & $\begin{array}{c}\text { Trabalhar e } \\
\text { melhorar a voz } \\
\text { cotidiana e/ } \\
\text { ou profissional } \\
\text { levando em conta o } \\
\text { contexto social }\end{array}$ & $\begin{array}{c}\text { Processual - encontros } \\
\text { semanais de uma a duas } \\
\text { horas ao longo de três a } \\
\text { quatro meses. } \\
\text { * } \\
\text { Tipos de abordagens: } \\
\text { dinâmicas; exercícios; teórica- } \\
\text { expositiva; diagnósticas } \\
* \\
\text { Processo educativo de } \\
\text { caráter transformador, } \\
\text { democrático, participativo, } \\
\text { dialógico, reflexivo, } \\
\text { problematizador relacionado } \\
\text { ao empoderamento para o } \\
\text { cuidado e a promoção da } \\
\text { saúde e qualidade de vida. }\end{array}$ \\
\hline $\begin{array}{c}\text { NEIVA } \\
\text { GAMA } \\
\text { TEIXEIRA } \\
(2016)^{16} \\
{ }^{16} \\
\text { Artigo em } \\
\text { Periódico }\end{array}$ & $\begin{array}{c}\text { Treinamento } \\
\text { "Expressividade vocal e } \\
\text { corporal para falar bem no } \\
\text { telejornalismo" } \\
* \\
\text { Coordenação: } \\
\text { fonoaudióloga } \\
* \\
\text { Ambiente Universitário - } \\
\text { projeto de pesquisa } \\
* \\
\text { Formal } \\
\text { (pesquisa) } \\
* \\
\text { Formação Inicial }\end{array}$ & $\begin{array}{c}\text { Estudantes de } \\
\text { Jornalismo }\end{array}$ & $\begin{array}{c}\text { Produção vocal } \\
* \\
\text { Saúde vocal } \\
* \\
\text { Pausas } \\
* \\
\text { Técnicas e } \\
\text { recursos vocais e } \\
\text { corporais } \\
* \\
\text { Oficina de texto e } \\
\text { locução }\end{array}$ & $\begin{array}{l}\text { Aprimorar o } \\
\text { desempenho } \\
\text { comunicativo em } \\
\text { telejornalismo. }\end{array}$ & $\begin{array}{c}\text { Pontual: dois encontros } \\
\text { de quatro horas (um por } \\
\text { semana). } \\
* \\
\text { Avaliação fonoaudiológica } \\
\text { pré-pós (recursos verbais e } \\
\text { não-verbais); psicodinâmica } \\
\text { vocal e parâmetros preferidos } \\
\text { na literatura } \\
* \\
\text { Auto-avaliação da } \\
\text { expressividade (impressões e } \\
\text { contribuições profissionais) } \\
\text { * } \\
\text { Dinâmicas de Grupos por } \\
\text { módulos: (1) entrosamento; } \\
\text { (2) produção vocal e saúde } \\
\text { da voz; (3) voz e corpo no } \\
\text { telejornalismo; (4) técnicas } \\
\text { vocais; (5) técnicas corporais; } \\
\text { (6) oficina de texto e locução. }\end{array}$ \\
\hline
\end{tabular}

\section{Discussão}

O estudo evidencia a escassez de publicações científicas referentes às experiências de atuação fonoaudiológica em práticas educacionais e processos de formação de jornalistas. As publicações se dão a partir de 2008, quando o tema da expressividade passou a ser mais considerado na Fonoaudiologia ${ }^{1}$.

As experiências estão ambientadas em Universidades e na maioria das vezes integram contextos formais de educação, geralmente com ações que se caracterizam como cursos, oficinas e vivências, desenvolvidas de modo processual como parte de projetos de pesquisa e extensão - o que evidencia o caráter efêmero das ações, uma vez que os projetos têm duração determinada e, após a sua finalização as experiências são interrompidas. As experiências são, portanto, focais, incipientes e experimentais.

Uma única situação integra as atividades curriculares e envolve o conjunto de alunos no contexto de uma disciplina de um curso de graduação em Jornalismo ${ }^{12}$ É possível perceber, portanto, que a atuação da Fonoaudiologia nas práticas educacionais de formação de jornalistas ainda não se encontra consolidada.

No tocante aos temas e conteúdos trabalhados, predominam: Expressividade e Saúde Vocal (100\%); Anátomo/fisiologia da Fonação ou Produção da Voz, Aquecimento/Desaquecimento Vocal, Exercícios Vocais e Psicodinâmica Vocal (57\% cada um deles). Nota-se que os temas/conteúdos confluem com abordagens de perspectiva organi- 
cista e fisiológica, bastante vinculada à vertente da saúde.

Algumas publicações ${ }^{11,14-16}$ agregam a preocupação com aspectos psico-sociais, contemplados na temática de Psicodinâmica Vocal, na relação entre a voz e aspectos de personalidade, sentimentos, emoções e os impactos psicológicos que a voz produz no outro.

Quanto à expressividade, a observação dos recursos/aspectos considerados/trabalhados e dos objetivos/enfoques a ela atribuídos evidencia a primazia dos aspectos/recursos vocais e a tendência a considerar a expressividade a partir destes recursos, o que condiz com achados de estudos anteriores sobre expressividade ${ }^{17}$, inclusive aqueles realizados especificamente com jornalistas ${ }^{10}$.

Há necessidades e dificuldades ainda a serem superadas na Fonoaudiologia, referentes às práticas de expressividade, identificadas em estudos anteriores ${ }^{18,19}$ : as restrições no emprego da terminologia expressividade, as divergências conceituais e de nomenclaturas dos recursos que a integram, dentre outras que consolidam a idéia de que avanços são necessários, nos modos de se conceber, pensar e trabalhar a expressividade.

O quadro 1 permite observar que os objetivos e enfoques atribuídos à expressividade geralmente se encontram circunscritos aos recursos expressivos e/ou à lógica da co-expressividade (sincronismo e coerência semântica entre os recursos vocais e não-verbais $)^{1}$. Os objetivos e enfoques atribuídos à expressividade estão centrados nas habilidades comunicativas/comunicacionais e atrelados à vertente da saúde.

Configura-se, assim, o caráter tecnicista/ instrumental das abordagens em $85 \%$ das publicações analisadas ${ }^{10,11,13,14,16}$, o qual muitas vezes está associado a enfoques restritos à realização de exercícios e à aplicação de técnicas e estratégias de desenvolvimento pautadas na prática clínica fonoaudiológica.

O caráter educativo/educacional, observado em somente $28 \%$ das publicações ${ }^{12,15}$, merece atenção especial neste estudo.

Autoras como Chieppe e Ferreira ${ }^{20}$, inspiradas em Antoni Zabala, consideram que o caráter educativo das práticas fonoaudiológicas dirigidas à promoção da saúde se encontra nas relações do trabalho fonoaudiológico com o ensino e a aprendizagem, uma vez que este otimiza habilidades e capacidades potenciais dos sujeitos, gerando opor- tunidades para seu desenvolvimento e formação integral, bem como de mudanças em suas relações interpessoais, inserção social, na sua saúde, seu bem-estar e em suas condições de trabalho e de vida. Neste sentido, a prática descrita na publicação de Penteado, Trevisan e Gonçalves ${ }^{12}$ pode ser considerada potencializadora das experiências dos educandos, nas relações com a realidade do mundo profissional e com os aspectos de saúde, trabalho e vida do jornalista.

A concepção de educação de Paulo Freire ${ }^{21}$ fundamenta as ações educativas descritas na publicação de Penteado e Santos ${ }^{15}$, de caráter transformador, democrático, participativo, dialógico, reflexivo e problematizador; entretanto o foco das ações se encontra centrado no cuidado e na promoção da saúde e da qualidade de vida.

Deste modo, se observa que o caráter educativo/educacional das práticas fonoaudiológicas na formação de jornalistas, nas poucas vezes em que é mencionado, se apresenta de maneira tênue e superficial, sem aprofundamento das concepções e propostas ou mesmo perspectivas mais amplas de educação.

Também é possível notar que as publicações não apresentam discussões que contribuam para o aprofundamento de uma concepção de expressividade que se substancie na configuração de outros processos educacionais implicados nas diferentes práticas sociais, contextos e atividades profissionais dos sujeitos envolvidos nas ações.

A expressividade, aprisionada nela mesma, não se presta à educação. A expressividade precisa ser compreendida e trabalhada nos contextos dos processos educacionais que, no caso particular de jornalistas e de professores, se dão nos espaços sociais midiático, escolar e não-escolar, de modo que é perpassada pelas relações de poder da sociedade e pelos interesses dos grupos e categorias que a constituem, que recaem sobre os vários sujeitos, atores sociais envolvidos e que se manifestam na linguagem, na expressividade.

Para autores como Markham ${ }^{22}$, o dinamismo, a fluidez e a expressividade, na prática jornalística, estão relacionados com a criatividade e com a ambivalência que esta exerce nas relações de poder e no processo de profissionalização do Jornalismo.

A expressividade precisa ser considerada de maneira mais ampla quando se trata das práticas que envolvem formação de comunicadores e de educadores, levando em conta a sua relevância, não 
somente no processo de formação dos profissionais, mas também no de profissionalização das categorias envolvidas e no de educação da sociedade que decorre das práticas sociais desempenhadas, por exemplo, por jornalistas e professores.

Outros estudos se fazem necessários para a discussão acerca das possibilidades de se pensar a expressividade de maneira mais ampla, nos contextos da cultura midiática da sociedade contemporânea, com destaque para os processos educacionais/ formativos em Comunicação e em Educação.

Além disto, é importante notar que a visão de educação, nas experiências que evidenciam um caráter educativo/educacional ${ }^{12}, 15$, está voltada para a promoção do cuidado e da saúde.

A educação é, sem dúvida, uma via relevante e necessária para a promoção do cuidado e da saúde, não somente junto aos comunicadores sociais, mas a todas as categorias de trabalhadores que usam a voz em seu contexto profissional ${ }^{23,24}$.

No entanto se observa que, nas publicações analisadas, o tema/conteúdo da saúde vocal geralmente é abordado apartado dos demais. Além disto, alguns estudos explicitam o enfoque restrito a uma estrutura específica, como na ação por viodeoconferência, em que a fonoaudióloga "alertou para cuidados que mantêm a saúde das pregas vocais" ${ }^{13}$.

A saúde vocal precisa ser abordada no conjunto e na complexidade da saúde geral das pessoas, categorias profissionais, comunidades e populações, o que implica em práticas desvencilhadas dos pressupostos higienistas e transformadas a partir de uma concepção positiva, ampla e dinâmica, de processo saúde-doença-cuidado, ambientado nas circunstâncias de vida e relacionado com a qualidade de vida, nas diversas dimensões e aspectos envolvidos nesse construto ${ }^{25}$.

O contexto de trabalho é uma das dimensões que comporta aspectos que atuam como determinantes e intervenientes do processo saúde-doença-cuidado. Entretanto só foram observadas relações explícitas entre a saúde e o trabalho do jornalista em uma publicação ${ }^{12}$. Estudos confirmam e apontam a necessidade de pesquisas e investimentos interdisciplinares na formação de uma cultura voltada para o cuidado, promoção da saúde e qualidade de vida dos jornalistas ${ }^{26}$.

Os resultados concernentes às estratégias de desenvolvimento das ações desenvolvidas nas publicações indicam que estas ainda se encontram enraizadas na prática clínica fonoaudiológica. Isso pode ser observado em situações como: aplicação de questionários que seguem roteiros de anamnese; a avaliação vocal individual; o emprego de modelos "preferidos" e/ou padronizados de narração/ locução/interpretação, pautados em formatos tradicionais de telejornalismo; além da transposição de práticas e de exercícios articulatórios empregados em terapias direcionadas a sujeitos com alterações de linguagem, fala, voz, respiração oral e motricidade orofacial - tal como as atividades de leituras de frases de trava-línguas ${ }^{10,14}$ que parecem infantilizadoras e descontextualizadas, ao ser transpostas da realidade clínica sem levar em conta as especificidades e diferenças de público-alvo, faixas etárias e ciclos de vida, ou de interesses, de realidades, de contextos e de produção do trabalho jornalístico.

As práticas fonoaudiológicas que envolvem a formação de profissionais de Comunicação e de Educação configuram um campo merecedor de atenção, de estudos e de investimentos em mudanças que se mostram necessárias. Nelas, as transformações devem ocorrer no sentido de possibilitar a potencialização do enfoque educacional, além de fazer da expressividade uma via para o estreitamento do diálogo entre Comunicação, Fonoaudiologia e Educação.

Esforços devem ser canalizados para a superação dos enfoques organicista/fisiológico, clínico-terapêutico, preventivista e tecnicista/ instrumental/comunicacional das ações, na direção de uma perspectiva sob enfoque educacional, que represente o alargamento da preocupação com o cuidado e a saúde e a ampliação de uma concepção de expressividade relacionada às práticas sociais contemporâneas e a processos educacionais que envolvem desenvolvimento humano, formação e humanização.

A ótica da Fonoaudiologia que recai sobre a expressividade precisa ser capaz de considerar e ressaltar, de modo atento e crítico, as contribuições desta área para as práticas sociais de Comunicação e de Educação, na contemporaneidade. É mister que as abordagens não se abstenham de um compromisso com o significado social de suas ações, e que os estudos e práticas fonoaudiológicas com a expressividade possam contribuir para enriquecer a reflexão acerca dos problemas educacionais existentes e colaborar com as possibilidades de enfrentamento - especialmente daqueles problemas que dizem respeito às práticas educativas escolares 
e daqueles atinentes ao trabalho docente e à formação de professores.

Entende-se que a atuação fonoaudiológica com a expressividade em contextos educacionais formadores no Ensino Superior pode concretizar mais um passo no caminhar e desenvolvimento das possibilidades de ressignificação e de legitimação da práxis da Fonoaudiologia Educacional, que ainda se encontra circunscrita à ambientação na Escola Básica e muito voltada à Acessibilidade e Educação Inclusiva.

As práticas fonoaudiológicas que envolvem a formação de profissionais de Comunicação e de Educação podem configurar mais uma via de contribuição para o necessário caminhar na direção do reconhecimento do fonoaudiólogo como membro das equipes educacionais em quaisquer níveis de ensino, bem como do seu papel na construção de práticas colaborativas específicas que, no contexto educacional, concorram para qualificar a Educação 27 - especialmente quando se trata da formação de profissionais das categorias que têm, na linguagem, na expressividade e na comunicação, alguns dos elementos fundamentais do trabalho.

\section{Conclusão}

O estudo de revisão mostrou que são poucas e incipientes as publicações que tratam das experiências de atuação da Fonoaudiologia em práticas educacionais e processos de formação de jornalistas, e a análise das publicações selecionadas para a revisão apontou as necessidades de ampliação das concepções de saúde, linguagem, expressividade e de educação que fundamentam essas práticas, bem como de potencialização do caráter educativo/ educacional do fazer fonoaudiológico.

As práticas fonoaudiológicas que envolvem a formação de profissionais de Comunicação e de Educação merecem destaque e atenção, especialmente em nelas potencializar o enfoque educacional. Nelas, a expressividade precisa ser repensada, uma vez que ela pode configurar uma chave no estreitamento do diálogo entre Comunicação, Fonoaudiologia e Educação na contemporaneidade.

\section{Referências}

1. Cotes C, Kyrillos L. Expressividade no telejornalismo: novas perspectivas. In: Oliveira IB, Almeida AF, Raize T, Behlau M. Atuação fonoaudiológica em voz profissional. São Paulo: Gen/ Roca, 2011. p.75-97.

2. Silva EC, Penteado RZ. Characteristics of innovations in television journalism and the expressiveness of the anchor. Audiol Commun Res. 2014; 19(1): 61-8.

3. Adam, GS. The education of journalists. Journalism, 2001; 2(3): 315-39.

4. Rita PA. Linguagem corporal à frente da bancada: a colaboração do não-verbal no telejornalismo. Anagrama, 2011; 4(2): 2-27.

5. Dias M. O novo telejornalismo e o desafio das práticas de ensino em sala de aula. Ed. Novas Edições Acadêmicas/ OmniScriptum GmbH \& Co. KG; Alemanha, 2015.

6. Kyrillos LR (org). Fonoaudiologia e telejornalismo: relatos de experiências na Rede Globo de Televisão. Rio de Janeiro: Revinter, 2003.

7. Feijó D, Kyrillos L. (org) Fonoaudiologia e Telejornalismo baseado no III Encontro Nacional de Fonoaudiologia da Central Globo de Jornalismo. Rio de Janeiro: Revinter, 2004.

8. Gama ACC, Kyrillos A, Feijó D. (org) Fonoaudiologia e Telejornalismo - Relatos do IV Encontro Nacional de Fonoaudiologia da Central Globo de Jornalismo. Rio de Janeiro: Revinter, 2005.

9. Kyrillos L, Cotes C, Feijó D. Voz e corpo na TV: a Fonoaudiologia a serviço da Comunicação. São Paulo: Globo, 2003

10. Trindade LLM. Julgamento do efeito de um programa de intervenção fonoaudiológica na expressividade oral de repórteres. Dissertação. Programa de Mestrado em Fonoaudiologia da Pontifícia Universidade Católica de São Paulo. São Paulo, 2008. Disponível em: http://www.sapientia. pucsp.br/tde_arquivos/16/TDE-2008-09-08T08:25:30Z-342/ Publico/Luciana\%20Leite\%20Mesquita\%20Trindade.pdf Acesso em: 29/03/2016.

11. Azevedo JBM, Ferreira LP, Kyrillos LR. Julgamento de telespectadores a partir de uma proposta de intervenção fonoaudiológica com telejornalistas. Rev. CEFAC. 2009; 11(2): 281-9.

12. Penteado RZ; Trevisan MAF; Gonçalves RB. Laboratório de voZ - um relato de experiência do processo de ensino na formação de jornalistas. Anais: 8a Mostra Acadêmica da UNIMEP e 8o Simpósio de Ensino de Graduação. Piracicaba, 2010. Disponível em: http://www.unimep.br/phpg/mostraacademica/ anais/8mostra/4/154.pdf Acesso em: 29/03/2016.

13. Cajazeira PESL. O papel social da voz para comunicadores: uma experiência extensionista em Rádio e TV. Conexão UEPG. 2013; 9(2): 290-7.

14. PERREGIL TC, SILVA TG. Os bastidores do Núcleo de Locução - Rádio Unesp Virtual. Anais: Intercom - Sociedade Brasileira de Estudos Interdisciplinares da Comunicação XVIII Congresso de Ciências da Comunicação na Região Sudeste Bauru - SP - 03 a 05/07/2013. p. 1-10. Disponível em: http:// portalintercom.org.br/anais/sudeste2013/resumos/R38-1085-1. pdf Acesso em: 29/03/2016. 
15. Penteado RZ, Santos VB. Ações educativas em grupos de vivência de voz. Distúrbios Comun. 2015; 27(2): 253-63.

16. Neiva TMA, Gama ACC, Teixeira LC. Vocal and body expressiveness to speak well in telejournalism: training results. Rev. CEFAC. 2016; 18(2): 498-507.

17. Tao J, Kang Y, Lin A. Prosody conversion from neutral speech to emotional speech. IEEE Transactions on Audio, Speech and Language Processing, 2006; 14(3): 1145-54.

18. Viola IC, Ghirardi ACA, Ferreira LP. Expressividade no rádio: a prática fonoaudiológica em questão. Rev Soc Bras Fonoaudiol. 2011; 16(1): 64-72.

19. Marquezin DMSS, Viola I, Ghirardi ACAM, Madureira S, Ferreira LP. Executives' speech expressiveness: analysis of perceptive and acoustic aspects of vocal dynamics. CoDAS. 2015; 27(2): 160-9.

20. Chieppe DC, Ferreira LP. Quando as práticas fonoaudiológicas são educativas. Distúrbios Comun. 2005;17(1): 123-6.

21. Menezes MG, Santiago ME. Contribuição do pensamento de Paulo Freire para o paradigma curricular crítico-emancipatório. Pro-Posições. 2014; 25(3): 45-62.
22. Markham T. The politics of journalistic creativity: expressiveness, authenticity and de-authorization. Journalism Practice. 2012; 6(2): 187-200.

23. Chun RYS, Servilha EAM, Santos LMA, Sanches MH Promoção da saúde: o conhecimento do aluno de jornalismo sobre sua voz. Distúrbios Comun., 2007; 19(1): 73-80.

24. Andrade BMR, Nascimento LS, Passos CRS, Nascimento UM, Souza GGA, Santos TC, Aguiar PRS, Castadena DFN, Valença EHO. Vocal characterization of the students of the Department of Social Communication of the Federal University of Sergipe. Distúrbios Comun. 2014; 26(4): 752-68.

25. Penteado RZ, Chun RYS, Silva RC. Do higienismo às ações promotoras de saúde: a trajetória em saúde vocal. Distúrbios Comun. 2005; 17(1): 9-17.

26. Penteado RZ, Gastaldello LM Health and quality of life of journalists: a review study. Rev Bras Promoç Saúde. 2016; 29(2): 297-304

27. Garcia VL. Formação do Fonoaudiólogo e sua atuação na área Educacional. In: Queiroga BAM, Zorzi JL, Garcia V (Orgs). Fonoaudiologia Educacional: reflexões e relatos de experiências. Brasília: Kiron, 2015. p.56-66. 